\title{
The Chinese Aspect System and its Semantic Interpretation
}

\author{
Guowen Yang and John A. Bateman
}

FB10, Sprach und Literaturwissenschaften

Bremen University, 28334 Germany

gwyang@uni-bremen.de bateman@,uni-bremen.de

\begin{abstract}
Motivated by a systematic representation of the Chinese aspect forms that explores their intrinsic semantics and temporal logical relations, we are constructing a Chinese aspect system network based on systemic functional grammar and implemented using the multilingual generator KPML. In this paper, we introduce the basic simple primary aspect forms and a set of secondary types of the unmarked-durative aspect in our Chinese aspect system, describe the semantic temporal relations of complex aspect in terms of temporal logic theories, and propose principled semantic conditions for aspect combination. Finally, we give a brief explanation of the system implementation.
\end{abstract}

\section{Motivation}

Chinese aspect is a traditional area of research that has always brought up questions and confusion for both theoretical and computational linguists. Our own practical motivation for exploring this area addresses two concerns. First, most existing research achievements in Chinese aspect have interpreted the semantics of Chinese aspect in intuitive and general terms rather than in terms of temporal logic theories however crucial for computational implementation. Second, Chinese linguists traditionally focus their attention on simple primary aspect (simple aspect) forms, but make no efforts either theoretically or computationally to deal with the large variety of complex aspects. Although the frequency of appearance of complex aspects is not as high as that of simple primary aspect types, they nevertheless play an important role in the Chinese aspect system and cannot be ignored. To meet these problems, we are constructing a complete Chinese aspect system in which

\footnotetext{
${ }^{1}$ Exception to this are Smith (1991) and Dai Y-J (1997) who have investigated Chinese aspect in terms of temporal logic theories. Their studies have focused particularly on simple aspect forms however.
}

all aspect expressions, including both simple primary aspect forms and complex aspect forms, are systematically organized. We are implementing the system using the KPML multilingual generator (Bateman, 1997), interpreting the intrinsic semantics of each aspect form in terms of existing temporal logic theories. In this paper we focus on the generation of complex aspect.

\section{The overview of Chinese complex aspect}

Both Chinese and English have complex aspect forms. Halliday (1976) describes forty eight possible forms of English tense and elaborates the ways in which the complex tense forms are combined. In Halliday's tense theory, the complex tense forms of English are recursively built up from primary tense to secondary tense, to tertiary tense, etc. Compared with English, the Chinese aspect system ${ }^{2}$ is rather different. In the Chinese aspect system, the combination of individual aspects is much more semantically restricted and much less grammatically regular than that in English. As a consequence, it gives rise to more difficulties in both theoretical explanation and practical implementation. We look into the details of this below.

We propose that the Chinese aspect system has barically seventeen simple primary aspect forms. They are shown diagrammatically in Figure 1.

\footnotetext{
${ }^{2}$ Chinese has no morphological tense markers. Tense in Chinese is realized lexically.

${ }^{3}$ It is our opinion that the Chinese aspect system is actually composed of both aspect morphemes (-le, -zhe, -guo4, etc.) and aspect adverbials (Yang, 1999, 2001)
} 


\begin{tabular}{|l|l|l|l|}
\hline \multicolumn{1}{|c|}{ name } & \multicolumn{1}{c|}{ form } & \multicolumn{1}{c|}{ name } & \multicolumn{1}{c|}{ form } \\
\hline \multirow{2}{*}{ unmarked-realized } & V+了(le) & unmarked-perfect & 已经(yi3jing1)+V+了(le) \\
\cline { 3 - 4 } \multirow{2}{*}{$\begin{array}{l}\text { unmarked- } \\
\text { experiential }\end{array}$} & V+过(guo) & $\begin{array}{l}\text { unmarked-perfect } \\
\text { experiential }\end{array}$ & 已经(yi3jing1)+V \\
\cline { 3 - 4 } & $\begin{array}{l}\text { marked-remote- } \\
\text { experiential }\end{array}$ & 曾经(ceng2jing1)+V+过(guo) \\
\hline recent-past-existing & $\begin{array}{l}\text { V+(N)+ 来着 } \\
\text { (lai2zhe) }\end{array}$ & unmarked-durative & V+着(zhe) \\
\hline activity-durative & 在(zai4)+V & long-durative & 一直(yi1zhi2)+V \\
\hline activity-progressive & 正在(zheng4zai4)+V & $\begin{array}{l}\text { unmarked- } \\
\text { progressive }\end{array}$ & 正(zheng4)+V \\
\hline start-and-continue & V+起来(qi3lai2) & continue-to-future & V+下去(xia4qu4) \\
\hline unmarked-future- \\
existing & 将(jiang1)+V & $\begin{array}{l}\text { written-imminent- } \\
\text { future-existing }\end{array}$ & $\begin{array}{l}\text { 将要/即将 } \\
\text { (jiang1yao4/ji2jiang1) } \\
+\mathrm{V}\end{array}$ \\
\cline { 3 - 4 } & & $\begin{array}{l}\text { spoken-imminent- } \\
\text { future-existing }\end{array}$ & 就要/快(jiu4yao4/kuai4)+V \\
\hline
\end{tabular}

Figure 1. The simple primary aspect forms

\begin{tabular}{|l|l|}
\hline \multicolumn{1}{|c|}{ name \& form } & \multicolumn{1}{c|}{ example } \\
\hline $\begin{array}{l}\text { long-and-unmarked-durative } \\
\text { 一直(yi1zhi2)+V+着(zhe) }\end{array}$ & $\begin{array}{l}\text { 诺克斯号一直航行着。 } \\
\text { nuo4ke4si1 hao4 yi1zhi2 hang2xing2 zhe } \\
\text { (The Knox has been sailing all along.) }\end{array}$ \\
\hline $\begin{array}{l}\text { marked-remote-experiential-unmarked- } \\
\text { durative } \\
\text { 曾经(ceng2jing1)+V+着(zhe) }\end{array}$ & $\begin{array}{l}\text { 那幅画曾经在这儿挂着。 } \\
\text { na4 fu2 hua4 ceng2jing1 zai4 zhe4er gua4 zhe } \\
\text { (That picture was once hanging here.) }\end{array}$ \\
\hline $\begin{array}{l}\text { recent-past-existing-unmarked-durative } \\
\text { V+着(zhe)+来着(lai2zhe) }\end{array}$ & $\begin{array}{l}\text { 那幅画刚才在这儿挂着来着。 } \\
\text { na4 fu2 hu4 gang1 cai2 zai4 zhe4er gua4 zhe lai2zhe } \\
\text { (That picture was hanging here just now.) }\end{array}$ \\
\hline $\begin{array}{l}\text { unmarked-realized-unmarked-durative } \\
\text { V+着(zhe)+了(le) }\end{array}$ & $\begin{array}{l}\text { 明天那幅画就在这儿挂着了。 } \\
\text { ming2tian1 na4 fu2 hua4 jiu4 zai4 zhe4er gua4 zhe le } \\
\text { (That picture will be hanging here from tomorrow.) }\end{array}$ \\
\hline $\begin{array}{l}\text { unmarked-perfect-unmarked-durative } \\
\text { 已经(yi3jing1)+V+着(zhe)+了(le) }\end{array}$ & $\begin{array}{l}\text { 那幅画现在已经在这儿挂着了。 } \\
\text { na4 fu2 hua4 xian4zai4 yi3jing1 zai4 zhe4er gua4 zhe le } \\
\text { (That picture is already hanging here now.) }\end{array}$ \\
\hline $\begin{array}{l}\text { unmarked-future-existing-unmarked-durative } \\
\text { 将(jiang1)+V+着(zhe) }\end{array}$ & $\begin{array}{l}\text { 明天那幅画将在这儿挂着。 } \\
\text { ming2tian1 na4 fu2 hua4 jiang1 zai4 zhe4er gua4 zhe } \\
\text { (That picture will be hanging here tomorrow.) }\end{array}$ \\
\hline unmarked-progressive-unmarked-durative \\
正(zheng4)+V+着(zhe) & $\begin{array}{l}\text { 那幅画现在正在这儿挂着。 } \\
\text { na4 fu2 hua4 xian4zai4 zheng4 zai4 zhe4er gua4 zhe } \\
\text { (That picture is hanging here now.) }\end{array}$ \\
\hline
\end{tabular}

Figure 2. The secondary types of unmarked-durative aspect

The "V" in the aspect forms denotes "verb"; the "/" shows disjunction; the name of each individual aspect was chosen based on its intuitive semantic function. The unmarkedperfect aspect 已经 $+\mathrm{V}+$ 了 (yi3jing $1+\mathrm{V}+\mathrm{le}$ ) is regarded as a simple aspect because it has the same function as the marked-perfect aspect 已经 $+\mathrm{V}$ (yi3jing1+V). They differ only lexically. The situation is the same for the unmarked-remote-experiential aspect 曾经 $+\mathrm{V}+$ 过 (ceng2jing1+V+guo) and the markedremote-experiential aspect 曾经 $+\mathrm{V}$ (ceng2 
jing1+V). The seventeen simple primary aspect forms belong to the three subsystems of perfective, imperfective (Comrie, 1976) or future-existing $\square$ according to the semantic properties in individual cases. Some simple primary aspect forms can combine to form various kinds of complex aspect. We call a combination involving two types of simple primary aspect an aspect of secondary type; the combination with three types of simple primary aspect is an aspect of tertiary type. By analogy, we also have an aspect of quaternary type; this is the maximum possibility: no further types are attested (Yang, 1999, 2001). The combination capacities of different simple primary aspect forms differ. For example, the simple primary aspect unmarked-durative $\mathrm{V}+$ 着 ( $\mathrm{V}+\mathrm{zhe}$ ), which belongs to the subsystem of imperfective, combines with several other types of simple primary aspect to construct complex aspect forms as shown in Figure 2. Some simple primary aspect forms, e.g. the simple primary aspect unmarked-experiential $\mathrm{V}+$ 过 $(\mathrm{V}+$ guo), have a very restricted capacity to combine with other simple aspect forms to build complex aspect forms.

\section{The semantic interpretation of Chinese complex aspect}

We briefly look into the profile of tense, aspect, and situation type, before examining closely the semantic temporal relations of complex aspect forms. We adopt Comrie's theoretical framework of tense and aspect. "As far as tense is concerned, then, the reference point is typically the present moment, and tenses locate situations either at the same time as the present moment, or prior to the present moment, or subsequent to the present moment..." (Comrie, 1985, p.14). "Aspects are different ways of viewing the

\footnotetext{
4 It is controversial whether to include "futurity" within the aspect category. We favor Halliday's tense theory (Halliday, 1976). We also agree with Bache's viewpoint "it seems to me not only convenient but also legitimate to accept future TEMPORALITY as a genuine member of the metacategory of tense" (Bache, 1995, p. 266). Compatible claims are also made by Dahl (Dahl, 1985, p.102-112). Also see Gong Q-Y (1995).
}

internal temporal constituency of a situation". (Comrie, 1976, p.3) Aspect is determined by the type of process ${ }^{-}$(in terms of systemic linguistics), the type of object, and the specific allocation of event initial time, speaking time and reference time. The aspectual properties of different kinds of event may be generalized in terms of Vendler's four situation types: states, activities, accomplishments, and achievements (Vendler, 1967). Situation types have nothing to do with the referential time of the event and are influenced only by process, object, and the time point or time interval over which the event holds.

We define several predicates to be used to express temporal relations based on and slightly altering those of Allen (1984). The important ones are:

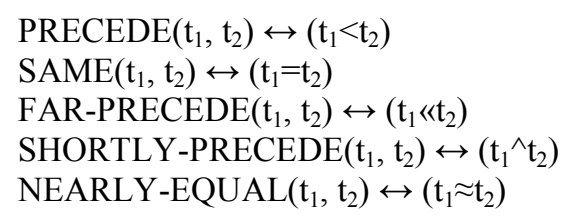

The predicates $\operatorname{PRECEDE}\left(\mathrm{t}_{1}, \mathrm{t}_{2}\right)$ and $\operatorname{SAME}\left(\mathrm{t}_{1}, \mathrm{t}_{2}\right)$ correspond to Allen's predicates $\operatorname{BEFORE}(\mathrm{t} 1, \mathrm{t} 2)$ and $\operatorname{EQUAL}(\mathrm{t} 1, \mathrm{t} 2)$ respectively. The difference between Allen's predicates and ours is that we use time points for definitions rather than time intervals. The reason for this slight change is that when the system is going to generate an aspect expression, either a simple aspect or a complex aspect, the breakdown into the relevant time points is often needed.

The predicate $\operatorname{PRECEDE}\left(\mathrm{t}_{1}, \mathrm{t}_{2}\right)$ indicates that the time point $t_{1}$ precedes the time point $t_{2}$ on the time axis. The predicate $\operatorname{SAME}\left(\mathrm{t}_{1}, \mathrm{t}_{2}\right)$ indicates that the time point $t_{1}$ equals the time point $t_{2}$ on the time axis. Three additional predicates are defined to meet the particular needs of expressing the temporal relations entailed by Chinese aspects. The predicate FAR-PRECEDE $\left(t_{1}, t_{2}\right)$ indicates that the time point $t_{1}$ precedes the time point $t_{2}$ considerably on the time axis. The predicate SHORTLY-PRECEDE $\left(\mathrm{t}_{1}, \mathrm{t}_{2}\right)$ indicates that

\footnotetext{
5 "A process consists potentially of three components: (i) the process itself; (ii) participants in the process; (iii) circumstances associated with the process." (Halliday, 1985, p.101)
} 
the time point $t_{1}$ only shortly precedes the time point $t_{2}$. The predicate NEARLYEQUAL $\left(t_{1}, t_{2}\right)$ indicates that the time point $t_{1}$ lies close to the time point $t_{2}$. We define $t_{i}, t$ t $t_{r}$, and $t_{s}$ as the event initial time, the event finishing time, the reference time, and the speaking time respectively.

From a theoretical point of view, to generate complex aspect forms not only must the temporal relations of individual aspect forms and the complex aspect forms be correctly represented, but the semantic requirements for the combination must also be met. What determines the combining possibility between different aspect forms is their own intrinsic logical temporal attributes. When the intrinsic logical temporal attributes of each aspect type are in harmony, the two aspect forms can combine; otherwise they cannot. We have observed the following principled conditions for this. First, it is feasible to express the process in each individual aspect form before the combination is made. Second, each individual aspect form has its own semantic function which is different from that of others. Third, in a specific situation, when two different aspect forms combine, the reference time points of each aspect type may move according to the temporal attributes of the combined aspect-however, no matter how reference time points change, the event initial time must remain unique, i.e. there must only be a single event initial time to which the complex aspect refers. If there is any conflict over this, the two aspects are incompatible with each other and the combination cannot be made. Finally, the combination must be in a proper order. This means that the selection of the aspect which is to serve as primary aspect has important consequences. We take two complex aspect forms as examples to illustrate these points.

The first example is the secondary aspect long-and-unmarked-durative 一 直 $+\mathrm{V}+$ 着 (yilzhi2+V+zhe). The combination is composed of two simple primary aspect forms: the unmarked-durative aspect $\mathrm{V}+$ 着 $(\mathrm{V}+\mathrm{zhe})$

\footnotetext{
${ }^{6}$ The $t_{f}$ here not only refers to the event intrinsic terminating point, which an event of accomplishment situation type usually has, but it also refers to the time point at which an event of other situation types is terminated by some kind of outside force.
}

(UDR) and the long-durative aspect 一直+V (yilzhi2+V) (LDR). Examples 1,2 and 3 illustrate the two simple primary aspect forms and the complex aspect respectively.

$$
\begin{array}{ccccc}
1 & \text { 诺克斯 } & \text { 号 } & \text { 航行 } & \text { 着 } \\
\text { nuo4ke4si } & \text { hao4 } & \text { hang2xin2 } & \text { zhe } \\
\text { the Knox } & \text { number } & \text { sail } & \text { UDR } \\
& \text { (The Knox is sailing.) } & &
\end{array}
$$

The simple primary aspect of unmarkeddurative is realized lexically by the marker “着 (zhe)”. The unmarked-durative aspect indicates either a dynamic or static durative state of the situation; it means that the situation begins before the reference time and is continuing at the reference time point. The temporal relations of the unmarked-durative aspect $\mathrm{V}$ +着 $(\mathrm{V}+\mathrm{zhe})$ are: $\mathrm{t}_{\mathrm{i}}<\mathrm{t}_{\mathrm{r}}$ and $\mathrm{t}_{\mathrm{r}}<\mathrm{t}_{\mathrm{f}}$. We presume further here, for present purpose, that $t_{r}=t_{s}$. Both $t_{i}$ and $t_{f}$ are unspecific time points: $t_{i}$ can be any time point before $t_{r}$, and $t_{f}$ can be any time point after $t_{r}$. This is represented graphically in Figure 3.

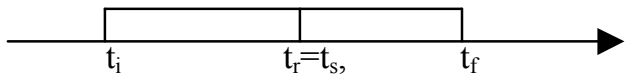

Figure 3. The temporal relations of the unmarkeddurative aspect $\mathrm{V}+$ 着 $(\mathrm{V}+\mathrm{zhe})$

\begin{tabular}{ccccc}
2 & 诺克斯 & 号 & 一直 & 航行 \\
nuo4ke4si & hao4 & yilzhi2 & hang2xing2 \\
the Knox & number & LDR & sail \\
\multicolumn{4}{c}{ (The Knox kept sailing until now.) }
\end{tabular}

The simple primary aspect long-durative, which is realized lexically by the marker "直 (yilzhi2)", indicates a relatively long durative state of the situation; it means that the process holds over a relatively long time duration from the event initial time to the event finishing time and that the event finishing time equals the reference time. The temporal relations of the long-durative aspect 一直 $+\mathrm{V}$ (yilzhi2 $+\mathrm{V}$ ) are: $\mathrm{t}_{\mathrm{i}} \ll \mathrm{t}_{\mathrm{f}}$, and $\mathrm{t}_{\mathrm{r}}=\mathrm{t}_{\mathrm{f}}=\mathrm{t}_{\mathrm{s}}$. This is represented graphically in Figure 4. The dotted line denotes the long duration. 


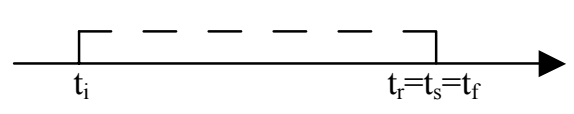

Figure 4. The temporal relations of the longdurative aspect 一直 $+\mathrm{V}$ (yi1zhi2+V)

3

$\begin{array}{ccc}\text { 诺克斯 } & \text { 号 } & \text { 一直 } \\ \text { nuo4ke4si1 } & \text { hao4 } & \text { yi1zhi2 } \\ \text { the Knox } & \text { number } & \text { LDR } \\ \text { 航行 } & \text { 着 } & \\ \text { hang2xing2 } & \text { zhe } & \\ \text { sail } & \text { UDR } & \end{array}$

(The Knox has been sailing all along.)

In example 3 , because the event initial time $t_{i}$ of the unmarked-durative aspect $\mathrm{V}+$ 着 $(\mathrm{V}+$ zhe) precedes the reference time point and it is an unfixed time point which can at any point precede the reference time, it can also be identical to the event initial time of the long-durative aspect 一直 $+\mathrm{V}$ (yilzhi2 $+\mathrm{V}$ ). The two individual aspect forms can share a unique event initial time so that a specific framework of temporal relations for the complex aspect can be established. In this case, we say that the two individual aspect forms are compatible; the combination can be made. The complex aspect indicates a long existing and continuing state of affairs with respect to the reference time. The temporal relations of the long-and-unmarked-durative 一直 $+\mathrm{V}+$ 着 (yilzhi2 $+\mathrm{V}+\mathrm{zhe}$ ) are then: $\mathrm{t}_{\mathrm{i}} \ll \mathrm{t}_{\mathrm{r}}$, $t_{\mathrm{r}}=t_{\mathrm{s}}$ and $\mathrm{t}_{\mathrm{r}}<\mathrm{t}_{\mathrm{f}}$. This is represented graphically in Figure 5.

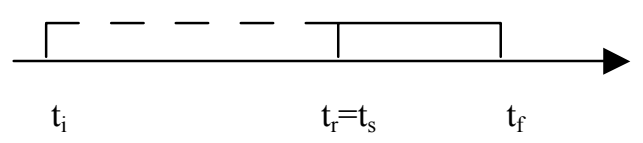

Figure 5. The temporal relations of the complex aspect long-and-unmarked-durative 一直 $+\mathrm{V}+$ 着

Comparing Figure 5 with Figure 3 and Figure 4 , we can see that for the unmarked-durative aspect $\mathrm{V}+$ 着 $(\mathrm{V}+\mathrm{zhe})$, the event initial time after the combination comes to 'far precede' the reference time. For the long-durative aspect - 直 $+V$ (yilzhi2 $+V)$, the event finishing time does not equal the reference time any more, which means that the situation is continuing.

The simple aspect forms differ in terms of how restricted they are in their usage with particular situation types or process types. In the design of the system network, it is necessary to arrange the logical dependencies such that less restricted aspect forms are made dependent on more restricted aspect forms. This avoids potentially incompatible logical conditions being required. For example, compared with other simple primary aspect forms, the unmarked-durative aspect $\mathrm{V}+$ 着 (V+zhe) (Figure 3) has more restricted requirements in its usage, therefore, it should be selected first; then it combines with the long-durative aspect 一直 $+\mathrm{V}$ (yilzhi2 $+\mathrm{V}$ ) to form the complex aspect long-and-unmarkeddurative 一直 $+\mathrm{V}+$ 着 (yil zhi2+V+zhe).

The secondary aspect long-and-unmarkeddurative 一直 $+\mathrm{V}+$ 着 (yilzhi2 $+\mathrm{V}+\mathrm{zhe}$ ) can further combine with another primary aspect, e.g. the unmarked-future-existing aspect (UFT) which is realized lexically by 将 (jiang1), to form a tertiary aspect type: 将+一 直 $+\mathrm{V}+$ 着 (jiang1+yilzhi2+V+zhe). We take this as another example to illustrate the aspect combining conditions; see example 4 below.

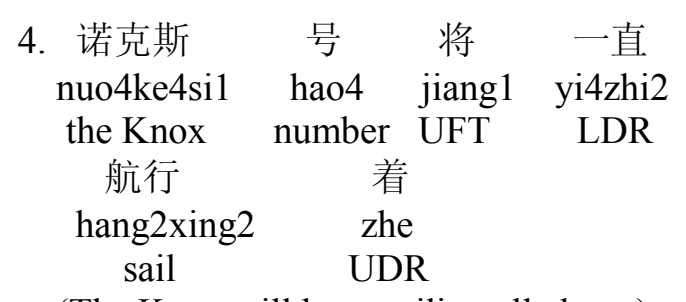

(The Knox will keep sailing all along.)

The unmarked-future-existing aspect 将 $+\mathrm{V}$ (jiang1+V) means that the process will hold sometime in the future. The temporal relations of the unmarked-future-existing aspect are: $\mathrm{t}_{\mathrm{r}}<\mathrm{t}_{\mathrm{i}},\left(\mathrm{t}_{\mathrm{i}}<\mathrm{t}_{\mathrm{f}}\right.$ or $\left.\mathrm{t}_{\mathrm{i}} \sim \mathrm{t}_{\mathrm{f}}\right)$. In example 4 , the temporal relation between $t_{i}$ and $t_{f}$ is $t_{i}<t_{f}$ but not $\mathrm{t}_{\mathrm{i}} \approx \mathrm{t}_{\mathrm{f}}$ which corresponds to an achievement situation. This is represented graphically in Figure 6.

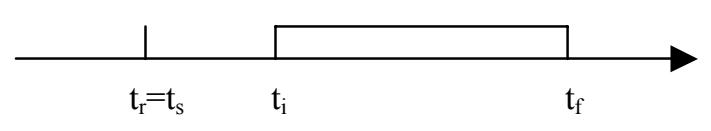

Figure 6 . The temporal relations of the unmarkedfuture-existing aspect 将 $+\mathrm{V}$ (jiang $1+\mathrm{V})$

When any aspect form combines with the unmarked-future-existing aspect, its own internal temporal relations as a whole will not be modified. The only change is that the event initial time may move. So when the long-andunmarked-durative aspect 一直 $+\mathrm{V}+$ 着 (yil 
zhi2+V+zhe) combines with the unmarkedfuture-existing aspect 将 $+\mathrm{V}$ (jiang1+V), the temporal relations of the long-and-unmarkeddurative aspect 一直 $+\mathrm{V}+$ 着 (yilzhi2+V+zhe) (Figure 5) become: $t_{s}<t_{i}, t_{i}\left\langle t_{r}\right.$, and $t_{r}<t_{f}$. This is represented graphically in Figure 7.

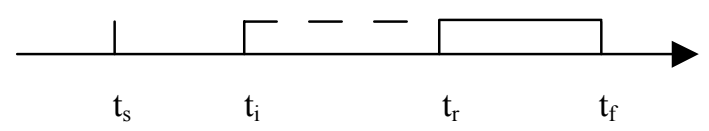

Figure 7. The temporal relations of the long-andunmarked-durative aspect

Compared with Figure 5, we can see that the reference time of the long-durativeunmarked-durative aspect 一直 $+\mathrm{V}+$ 着 (yi1 zhi2 $+\mathrm{V}+\mathrm{zhe}$ ) has moved, from $\mathrm{t}_{\mathrm{r}}=\mathrm{t}_{\mathrm{s}}$ to $\mathrm{t}_{\mathrm{s}}<\mathrm{t}_{\mathrm{r}}$, and the event initial time correspondingly changes from $t_{i}<t_{s}$ to $t_{s}<t_{i}$.

Because the event initial time $t_{i}$, which is inherited from the long-and-unmarkeddurative aspect 一直 $+\mathrm{V}+$ 着 (yil zhi2 $+\mathrm{V}+\mathrm{zhe}$ ), is unique, and the reference time $t_{r}$ equals the speaking time $t_{s}$, the tertiary aspect 将 + 一直 $+\mathrm{V}+$ 着 (jiang1+yi1zhi2+V+zhe) has the following temporal relations: $t_{i} \ll t_{f}$ and $t_{r}<t_{i}$ and $t_{r}=t_{s}$. This is represented graphically in Figure 8.

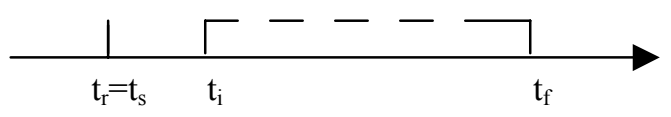

Figure 8 . The temporal relations of the tertiary aspect unmarked-future-existing-long-durativeunmarked-durative 将 + 一直 $+\mathrm{V}+$ 着 (jiang1+yi1zhi2 $+\mathrm{V}+$ zhe)

We can see from Figure 8 that although the viewpoint of the situation changes after the combination, a unique event initial time can nevertheless be established. The event initial time of the long-and-unmarked-durative aspect 一直 $+\mathrm{V}+$ 着 (yi1zhi2 $+\mathrm{V}+\mathrm{zhe}$ ) still functions in the complex aspect.

Now let us look into one further example to see the situation when two aspect forms cannot combine. The simple primary aspect long-durative 一直 $+\mathrm{V}$ (yilzhi2+V) and the simple primary aspect activity-progressive (APG), which is lexically realized by the marker 正在(zheng4zai4), are not compatible. The two aspect forms cannot combine. Example 5 is unacceptable.

\section{5. * 诺克斯

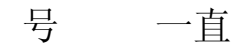 \\ nuo4ke4si1 \\ hao4 yilzhi2 \\ the Knox \\ number LDR \\ 正在 \\ zheng4zai4 \\ APG \\ 航行 \\ hang2xing2 \\ sail}

(* The Knox has been being sailing all along.)

The activity-progressive aspect 正在 $+\mathrm{V}$ (zheng4zai4+V) indicates a dynamic progressive state of the situation holding since a specific time point (event initial time $t_{i}$ ). Its temporal relations are: $t_{i}=t_{r}$ and $t_{i}<t_{f}$. This is represented graphically in Figure 9.

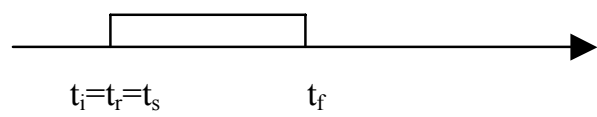

Figure 9. The temporal relations of the unmarkedprogressive aspect 正在 $+\mathrm{V}$ (zheng4zai4+V)

Comparing the temporal relations of the longdurative aspect 一直 $+\mathrm{V}$ (yilzhi2 $+\mathrm{V})$ in Figure 4 with the temporal relations of activity-progressive aspect 正在 $+\mathrm{V}$ (zheng4 zai4+V) in Figure 9, we can see that the two aspect forms have obviously different event initial time points. One has an event initial time which precedes the reference time; another has an event initial time which equals the reference time. A unique event initial time cannot be found. Therefore the two types of aspect are incompatible and cannot combine.

\section{The implementation of the system}

To generate a specific aspect expression, temporal relations as described in the last section must be taken. Semantic inputs representing the temporal relations are a set of time points $t_{i}, t_{f}, t_{r}$, and $t_{s}$. Each of the time points is expressed in a specific concept, which could correspond to a specific time value, showing its relative position on the time axis; e.g. at-past, at-present, or at-future. The semantic inputs are represented in the form of a set of examples making up a testsuite. Using the predicates described in section 3, appropriate temporal relations can be automatically built by the system. Then the system traverses a grammar network and chooses appropriate grammatical features by use of relevant inquiries and choosers (Matthiessen \& Bateman, 1991, Teich \& 
Henschel, 1991). The main function of choosers is to guide traversal of the grammar and choose grammatical features by asking the relevant inquiries and testing all the required conditions that they give. An inquiry contains a set of conditions to test whether the given inputs meet some set of semantic requirements. For example, the inquiry used to test the unmarked-durative aspect $\mathrm{V}+$ 着 $(\mathrm{V}+\mathrm{zhe})$ contains the following conditions: $t_{\mathrm{i}}$ precedes $t_{r}, t_{r}$ precedes $t_{f}, t_{r}$ same as $t_{s}$, the process is not of intensive-relational type with verbs like 是 (shi4, be) or adjectives describing properties, and not of possessive type with verb 有 (you3, have). Once a feature is chosen, realization rules attached to the feature place constraints on lexical selection and syntactic structure. Following traversal of the grammar the combined lexical and grammatical constraints are resolved in order to give the final lexicalized grammatical structure.

\section{Conclusion}

In this paper, we have introduced the basic simple primary aspect forms and a set of secondary types of the unmarked-durative aspect $\mathrm{V}+$ 着 $(\mathrm{V}+\mathrm{zhe})$ in our Chinese aspect system, described the semantic temporal relations of complex aspect forms in terms of temporal logic theories, and proposed principled semantic conditions required for aspect combination. In respect of aspect, English and Chinese are semantically rather different. As future work we are now investigating potential applications of our description in several areas. In addition to the generation of Chinese texts per se, we are also considering the use of multilingual generation in, for example, contrastive reference grammars, and language teaching.

\section{References}

Allen, J.F. (1984) Towards a General Theory of Action and Time, Artificial Intelligence, 1984, 23, p.123-154

Bache, C. (1995) The Study of Aspect, Tense and Action: Towards a Theory of the Semantics of Grammatical Categories. Frankfurt/M.: Lang.

Bateman, J.A. (1997) Enabling technology for multilingual natural language generation: the KPML development environment, Natural Language Engineering, 3(1), p.15-55
Comrie, B. (1976) Aspect, Cambridge, England: Cambridge University Press.

Comrie, B. (1985) Tense, Cambridge, England: Cambridge University Press.

Dahl, Ö. (1985) Tense and Aspect Systems, Oxford: Blackwell.

Dai, Y-J. (1997) 现代汉语时体研究 (A Study of Chinese Aspect), Zhejiang Education Publisher.

Gong, Q-Y. (1995) 汉语的时相, 时制, 时态 (Phase, Tense and Aspect in Chinese), Beijing: Commercial Press.

Halliday, M.A.K. (1976) System and Function in Language, Oxford University press.

Halliday, M.A.K. (1985, first edition) (1994, second adition) An Introduction to Functional Grammar, Edward Arnold, London.

Matthiessen, M.I.M. \& Bateman, John A. (1991) Text Generation and Systemic-Functional Linguistics, Pinter Publishers, London

Smith, C.S. (1991) The Parameter of Aspect, Dordrecht: Kluwer Academic.

Teich, E. \& Henschel, R. (1991) Aspect choice in a fragment of a systemic grammar of Russian, GMD-IPSI, Germany.

Vendler, Z. (1967) Linguistics in Philosophy, Ithaca: Cornell University Press.

Yang, G-W. (1999) 汉语 “复合态” 的语义关系 类型及其生成的有向性 (The semantic relation types of complex aspect and the directional requirements in generation), in Proceedings of the $5^{\text {th }}$ Chinese Conference on Computational Linguistics, Tsinghua University Press, Beijing, p.21-26

Yang, G-W. (2001) 汉语态制中 “复合态” 的生 成 (The Generation of Chinese Complex Aspect), Zhong1Guo2 Yu3Wen2, 2001 No 5, p. $418-427$ 